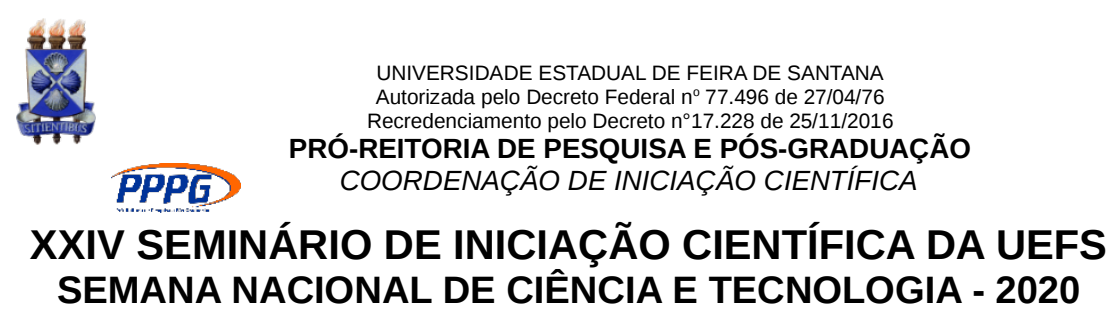

\title{
SAÚDE MENTAL EM FEIRA DE SANTANA, BAHIA: ANÁLISE DE PUBLICAÇÕES DO JORNAL FOLHA DO NORTE (1921-1950)
}

\author{
Rebeca Ribeiro Ferreira $^{1}$; Suzi de Almeida Vasconcelos Barboni² \\ 1. Bolsista PROBIC/UEFS, Graduanda em Psicologia, Universidade Estadual de Feira de Santana, e-mail: \\ rebeca.ribeiro20.rr@gmail.com \\ 2. Orientadora, Departamento de Ciências Biológicas, Universidade Estadual de Feira de Santana, e-mail: \\ suziavbarboni@gmail.com
}

PALAVRAS-CHAVE: Saúde Mental; Saúde Pública; Feira de Santana.

\section{INTRODUÇÃO}

Sobre Saúde Mental sabe-se que é um campo de marginalização e exclusão tanto pelo senso comum como pela psiquiatria tradicional. Difícil de conceituar, a própria Organização Mundial da Saúde (OMS) afirma que não existe uma definição oficial considerando as variáveis que norteiam o termo ${ }^{1}$. Segundo DE SOUZA; BAPTISTA (2008) a complexidade de conceituar Saúde Mental provém da relação que esse campo estabelece com cada cultura, momento histórico e povo. O chamado "comportamento normal” é tido como a conduta seguida pela maioria das pessoas que compõem determinada sociedade, e a loucura é o “comportamento desviante”.

No Brasil a assistência psiquiátrica foi historicamente embasada em ações médicas caracterizadas por longas internações, violência e negligência, presentes nos serviços de saúde até pouco tempo atrás quando foi estabelecida a Reforma Psiquiátrica. Até então, a Saúde Mental estava implicada na ordem pública, livrando "a sociedade da escoria, desfazendo-se dela, de preferência em local que a vista não pudesse alcançar” (ARBEX, 2013). Era a legitimação do poder do Estado em Saúde Mental a quem caberia organizar e promover ordem nos respectivos territórios que governavam, como autoridades que elaboram leis, normas, e, atribuem aos cidadãos responsabilidades éticas e sociais. Aqueles que não obedecem às leis perturbam a normalidade estabelecida, passam a estar à margem da sociedade e devem ser segregados.

A Atenção em Saúde Mental na cidade de Feira de Santana (FSA), situada na região do semi-árido do Estado da Bahia, distante 108 quilômetros da capital, atualmente a segunda cidade do Estado, tem fortes raízes nas décadas de 60 do século XX, com a fundação do Hospital Colônia Lopes Rodrigues, focado modelo biomédico higienista, no isolamento, na segregação e em intensas atividades laborativas no setor da agricultura.

Como campo de intervenção, cuidados e estudos, a Saúde Mental em FSA não teve muitos registros históricos ou jornalísticos de forma sistematizada uma vez que este silenciamento proposital diz respeito ao estigma da doença mental sempre olhada sob os ditames da ordem pública e da moral médica como identificado por Santana; Barboni (2020). Assim, este estudo visa contribuir para o esclarecimento deste vazio na história da cidade, no início do século $\mathrm{XX}$, a partir do olhar de uma fonte jornalística.

1

Aspectos sócio-histórico-culturais e julgamentos subjetivos afetam o modo como a "saúde mental” é definida. É mais amplo que a ausência de transtornos mentais. 


\section{METODOLOGIA}

Pesquisa de cunho exploratório, de caráter qualitativo e histórico, com buscas em material jornalístico e pesquisa bibliográfica no período 1921-1950.

A fonte de pesquisa foi o Jornal Folha do Norte (JFN) criado em 17 de setembro de 1909 em FSA, um dos mais antigos do Estado da Bahia (ainda em funcionamento), “(...) de tendência política conservadora, já que atendia muitas vezes a interesses específicos e a um grupo da população considerada como elite" representada pelos ricos fazendeiros, professores, e outros letrados enquanto a maior parte do povo feirense era analfabeta (SANTANA; BARBONI, 2020, p. 153). O JFN é uma das importantes fontes de resgate da história de FSA permitindo a análise da identidade da cidade em suas tradições conservadoras, do ponto de vista das elites, identificadas com o "progresso" por reproduzir e confirmar informações e visões homogêneas na perspectiva da classe dominante. A aproximação do estudo com a prosopografia do grupo "elite" permite entender trajetória e representações da saúde mental expressas pelo JFN. Os exemplares publicados nos primeiros quarenta e um ano editoriais, encontram-se digitalizados e disponíveis no Museu Casa do Sertão da Universidade Estadual de Feira de Santana (UEFS), utilizados nesta pesquisa.

A análise dos achados jornalísticos foram tratadas com referenciais da análise temática (BARDIN, 1979) - análise de conteúdo, a partir da exploração textual, identificando os elementos de esclarecimento do texto (autoria, fatos, ideologias e estilo) e a estrutura redacional (seções, estilo, etc.), com destaque nas representações, expectativas e argumentos elucidados e demarcados os núcleos de sentido, suas principais categorias, que possibilitaram 0 reconhecimento das práticas discursivas que configuraram o campo da Saúde Mental na cidade dentro do recorte temporal proposto. Na fase interpretativa buscou-se tecer relações críticas entre as ideias e o contexto histórico, com base no levantamento bibliográfico.

A partir dos dados obtidos investigou-se o cenário e identidades acerca da Saúde Mental e Saúde Pública de FSA no período de 1921-1950, através de notícias, anúncios, propagandas e outras publicações do JFN. As publicações foram categorizadas em notícias, divulgação de serviços e difusões sobre saúde em geral e sobre saúde mental.

RESULTADOS E DISCUSSÃO

Identificou-se nos exemplares pesquisados do JFN dentro do recorte temporal de 19211950, anúncios e propagandas de medicamentos considerados "populares", com investida higienista, que revelam o modelo curativista de atenção à saúde, com foco nos consumidores de medicamentos. Verificou-se que grande parte dos anúncios relacionados à saúde continham propagandas para enfermidades físicas, a maioria direcionada às mulheres que "sofrem de doenças do útero, flores brancas, suspensões, hemorragias”. Com esses achados, a pesquisa passou a ter um olhar mais sensível aos aspectos femininos na cidade de FSA, em especial àquelas que poderiam sofrer influência do JFN por terem acesso a imagens e valores ali disseminados.

Assim, foram localizadas cinco propagandas de medicamentos que remetiam a saúde mental: "Saúde da Mulher", "Regulador Gesteira”, "Fluxo-Sedatina”, "Vikelp” e "Sedocalmol”. Os três primeiros eram direcionados ao humor feminino, referenciados como "incommodos provenientes da mudança de idade", "incommodos dos nervos" ou "incommodos das senhoras e senhoritas". O quarto medicamento, "Vikelp" apesar de não ser claramente direcionado a aspectos mentais, fazia menção a saúde mental no tocante beleza física e "bom humor". O quinto medicamento, "Sedocalmol", é o único que foi indicado para tratamento no âmbito da saúde mental. Trata-se de um medicamento para a insônia e, assim como os demais medicamentos citados, faz associação entre o medicamento e o bem-estar.

O uso de palavras e adjetivos pejorativos (perturbações, incômodos e irregularidades) em propagandas de medicamentos para mulheres, desconsideravam o fenômeno natural do ciclo hormonal feminino, inerente à idade reprodutiva, que em períodos de oscilação hormonal apresentam certos sinais emocionais e físicos típicos. 
As propagandas de medicamentos refletiam a representação social da época como "mulheres para o casamento e ter filhos": "Saúde da Mulher”, "Regulador Gesteira” e "FluxoSedatina", indicados exclusivamente para o público feminino que passa por alterações hormonais periodicamente, e, por consequência, experiencia intensa oscilação de humor. Este dado remete ao estudo realizada por Rohden (2001 apud Rago, 2002) do qual analisou teses produzidas na Faculdade de Medicina do Rio de Janeiro (fins do século XIX e início do século XX), e constatou a associação entre sexualidade feminina e loucura, tratando dos temas: puberdade, menstruação, loucura, onanismo, ninfomania, neurastenia, prostituição, desejo, menopausa, histeria, casamento e amor.

Percebe-se nas propagandas de medicamentos direcionados ao humor feminino, referenciados como "incommodos provenientes da mudança de idade", o foco na juventude "sendo o período da puberdade muito propício ao aparecimento de doenças, como a clorose, a histeria, a loucura, a ninfomania, essa fase precisaria de cuidados muito especiais" (ROHDEN, 2001 apud RAGO, 2002, p. 514). Reforça este achado um estudo conduzido por Cunha (1998) com os prontuários do Juquery, do início do século XX, que trata "da consideração de uma inferioridade "natural" como marca das histórias de mulheres em situação de internamento”. Ou seja, havia um padrão de feminino saudável - o das mulheres "de família" - com condutas classificadas como "normais", dentro de papeis estabelecidos, isto é, fortemente vinculadas, de uma forma orgânica e psicológica, à família (PEGORARO; CALDANA, 2008).

Neste conjunto de propagandas analisado é explícito o julgamento moral e social na figura feminina. Isto porque as propagandas de medicamentos pareciam pretender inculcar nos leitores que a natureza das mulheres era mais fraca, levando à indisposição orgânica; que estas eram propensas à incômodos, fazendo do "ser mulher" algo naturalmente predisposto ao adoecimento, tanto físico como "dos nervos". Percebe-se que as questões de gênero eram fundamentais para uma indústria farmacêutica nacional que a partir da década de 1930 cresce vertiginosamente, equiparando-se tecnicamente com as indústrias estrangeiras tornando-se forte e poderosa no caráter mercantil até os dias atuais (RODRIGUES, 2015).

Em todos os dados coletados identificou-se mensagens sobrepostas nas propagandas de medicamentos as quais fazem alusão à gênese das enfermidades mentais, na época restritas a oscilações de humor e perda de sono, em especial, nas mulheres. Como produtores da verdade, os anúncios transmitiam a ideia de que os problemas de saúde mental têm origem física, e apresentam soluções individuais como a prática da automedicação incentivando consumo de determinado medicamento que acenava com promessas de cura e felicidade, por apagarem sinais e sintomas. É a dinâmica de dominação propagando "representações unilaterais e homogêneas da realidade, apresentadas como sendo a própria realidade ou o que importa dela” (BIROLI, 2011).

Observou-se que a preocupação com a saúde mental e a saúde feminina partem exclusivamente de iniciativas médico-farmacêuticas, com características privadas, sem participação do Poder Público ou recomendações de práticas integrativas de cura, que estão silenciados. Esta visão comercial da saúde é importante elemento do mesmo mecanismo ideológico acionado ao longo do século XX, no qual a indústria farmacêutica propaga o ideal de saúde e qualidade de vida associado ao consumo de medicamentos, perspectiva que está presente nos anúncios coletados na JFN. O apelo mercadológico persiste nos dias atuais, apesar das restrições da Agência Nacional de Vigilância Sanitária (ANVISA) - que desde 2008 dispõe da Resolução RDC $\mathrm{N}^{\circ}$ 96, que regulamenta critérios para propaganda, publicidade, informação e outras práticas de promoção comercial de medicamentos (BRASIL, 2008).

\section{CONSIDERAÇÕES FINAIS}

No período estudado (1921-1950) a saúde mental em FSA aparece no corpo do JFN de forma sutil a partir de propagandas e anúncios de medicamentos com referências à figura feminina, percebida como vítimas de "incômodos provenientes da mudança da idade”. Os achados apontam à gênese dos estereótipos em torno do gênero feminino negligenciando como a produção social gerava sofrimento psíquico ao apresentar as consequências das relações 
opressoras como próprias, naturais da mulher. A hegemonia do modelo biomédico sustentava essa concepção ao passo que visava somente silenciar o corpo, não tratar as mentais, afetando assim a compreensão social do adoecimento psíquico que era tido como resultado de um mal funcionamento fisiológico sem conexão com o contexto social. Este estereótipo inculcado sobre a mulher da elite feirense da época pode ter influenciado a saúde pública determinando a forma de atendimento médico.

Fenômenos referentes à oscilação hormonal como menstruação, puerpério e menopausa foram indicados nos achados como "mal-estar feminino", ainda que todos sejam caracterizados por alterações hormonais naturais que podem conduzir a oscilações de humor, condicionando o processo de sofrimento para a mulher. Essas oscilações emocionais foram apresentadas em propagandas de medicamentos femininos como aspecto negativo, incitando o rechaço e exclusão do ser natural.

Faz-se necessário destacar a fundamental importância do trabalho interdisciplinar no campo da saúde mental, reforçar olhar crítico na práxis da saúde pública atual e o trato da doença mental e sua relação com as convenções estabelecidas na sociedade. A contribuição históricosociológica sobre o tema fornecida pela presente pesquisa aponta a necessidade de maior atenção a subjetividade das usuárias nos serviços de saúde mental do Sistema Único de Saúde (SUS).

\section{REFERÊNCIAS}

ARBEX, Daniela. Holocausto brasileiro. 1.ed. São Paulo: Geração Editorial, 2013. BARDIN, L. Análise de conteúdo. Lisboa: Edições 70. 226p.1979.

BIROLI, Flávia. Mídia, tipificação e exercícios de poder: a reprodução dos estereótipos no discurso jornalístico. Rev. Bras. Ciênc. Polít., Brasília ,n. 6,p. 71-98, Dec.2011 . BRASIL; Resolução da Diretoria Colegiada (RDC) $n^{\circ}$ 96, de 17 de dezembro de 2008.

BRASIL. Dispõe sobre a propaganda, publicidade, informação e outras práticas cujo objetivo seja a divulgação ou promoção comercial de medicamentos. Ministério da Saúde; Agência Nacional de Vigilância Sanitária. Diário Oficial da União, 2008.

CUNHA, M. C. P. De historiadoras, brasileiras e escandinavas: loucuras, folias e relações de gêneros no Brasil (século XIX e início do XX). Tempo, Rio de Janeiro, v. 3, n. 5, p. 181-215, 1998.

DEFINIÇÃO DE SAÚDE MENTAL. Secretaria da Saúde. Disponível em:

http://www.saude.pr.gov.br/modules/conteudo/conteudo.php?conteudo=1059. Acesso em: 25 fev. 2019.

DE SOUZA, M. S.; BAPTISTA, M. N. Associações entre suporte familiar e saúde mental. Psicologia Argumento, v. 26, n. 54, p. 207-215, 2008.

PEGORARO, R. F.; CALDANA, R. H. L. Mulheres, loucura e cuidado: a condição da mulher na provisão e demanda por cuidados em saúde mental. Saúde e Sociedade, São Paulo, v. 17, n. 2, p. 82-94, 2008.

QUEIROZ, C. M. B.; SÁ, E. N. C.; ASSIS, M. M. A. Qualidade de vida e políticas públicas no município de Feira de Santana. Ciência \& Saúde Coletiva, v. 9, p. 411-421, 2004.

RAGO, E. J. A construção da 'natureza feminina' no discurso médico. Estudos feministas, Florianópolis, ano 10, n. 514, p. 511-514, jul./dez. 2002.

RODRIGUES, G. K.; et al. Não há cura sem anúncio: ciência, medicina e propaganda (São Paulo, 1930-1939).2015. 186 f. Dissertação de Mestrado. Pontifícia Universidade Católica de São Paulo, São Paulo, 2015.

SANTANA, A. C. DE S.; BARBONI, S. DE A. V. Saúde mental na cidade de Feira de Santana, Bahia: análise de notícias, anúncios e serviços publicados no Jornal Folha do Norte (1909-

1921). Ponta de Lança: Revista Eletrônica de História, Memória \& Cultura, v. 14, n. 26, p. 151 170, 20 jul. 2020. 